\title{
ZIF-8-derived Hollow Polyhedra Modified Graphene Oxide Membranes for Organic Solvent Nanofiltration with Enhanced Permeance
}

Naixin Wang, Hao Sun, Hengyu Yang, Xiaoting Li, Shulan Ji, Quan-Fu An*

Beijing Key Laboratory for Green Catalysis and Separation, College of

Environmental and Energy Engineering, Beijing University of Technology, Beijing

100124, P. R. China 


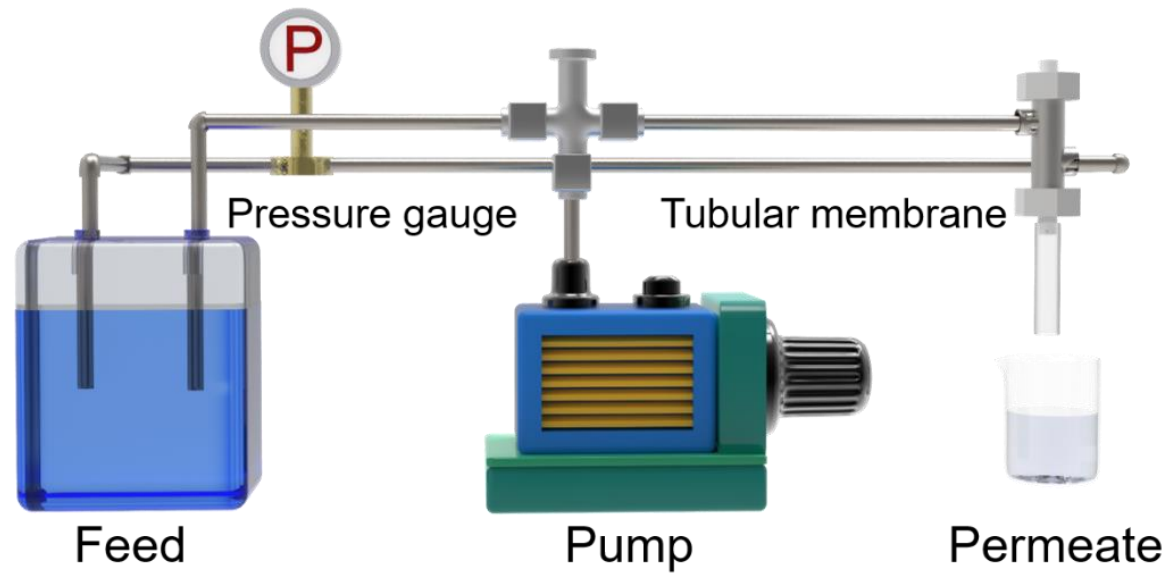

Figure S1. Schematic diagram of organic solvent nanofiltration experimental device.

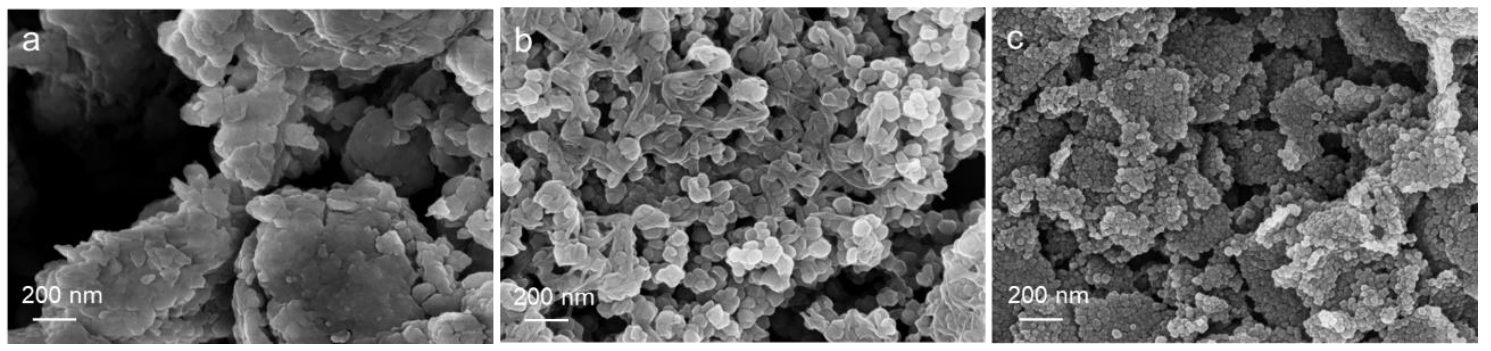

Figure S2. Molar ratio of metal ion $\left(\mathrm{Zn}^{2+}\right)$ to organic ligand (Hmim): a) 1:2, b) 1:4, c)

1:8.

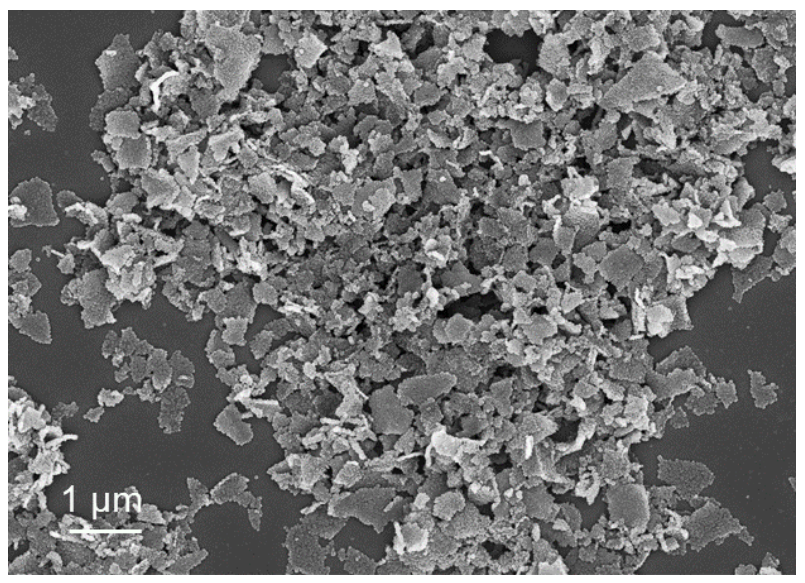

Figure S3. SEM images of ZnS@GO laminates. 

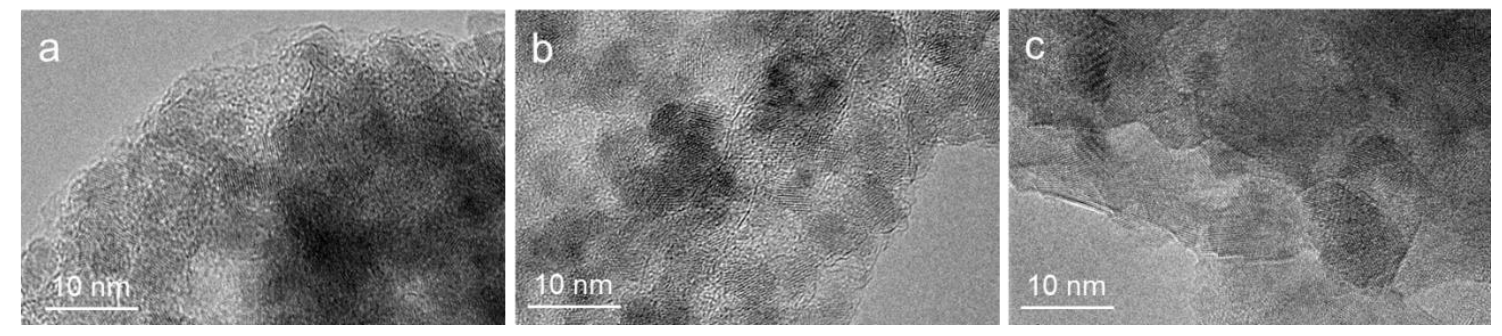

Figure S4. TEM images of ZnS@GO laminates at different sulfurizing times: a) 30 $\min$, b) $45 \mathrm{~min}$, c) $60 \mathrm{~min}$.

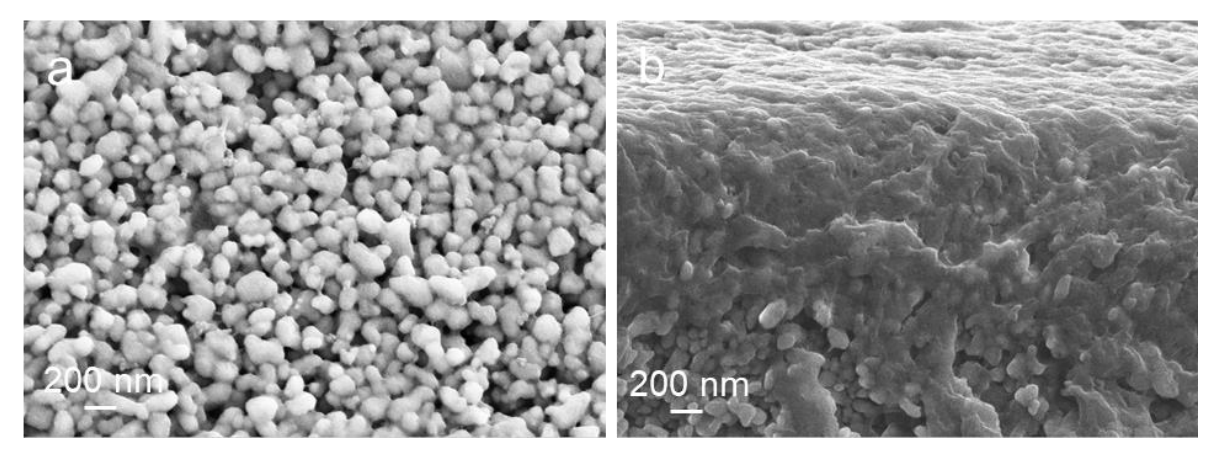

Figure S5. Surface and cross-sectional morphology of PEI composite membrane.
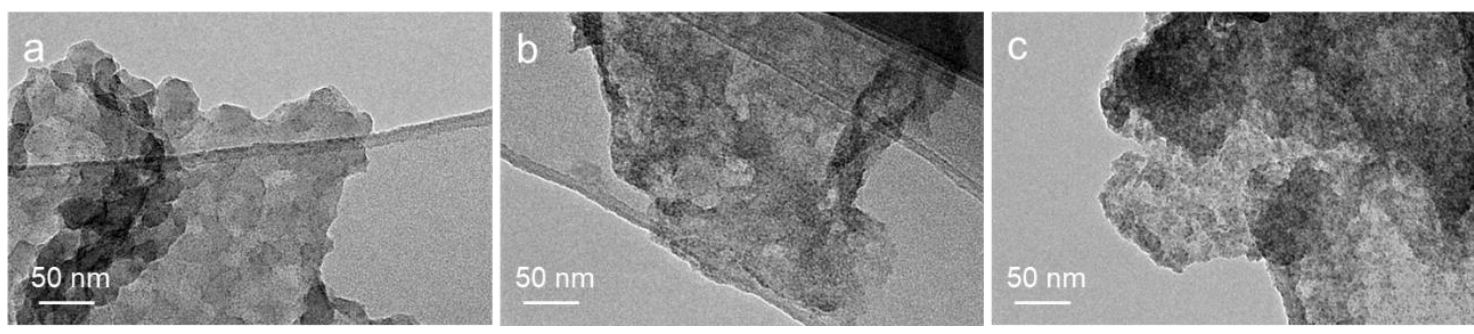

Figure S6. TEM images of ZnS@GO laminates at different TAA concentrations: a)

$$
0.01 \mathrm{~mol} / \mathrm{L}, \mathrm{b}) 0.05 \mathrm{~mol} / \mathrm{L}, \mathrm{c}) 0.08 \mathrm{~mol} / \mathrm{L} \text {. }
$$

